\title{
Ontology Model of a Robotics Agents Community
}

\author{
H. Latorre, K. Harispe, R. Salinas, G. Lefranc
}

\author{
Homero Latorre Karina Harispe \\ Universidad Tecnológica Metropolitana de Chile \\ Departamento de Informática y Computación \\ José Pedro Alessandri 1242, Nuñoa. Santiago - Chile \\ E-mail: helatorre@gmail.com
}

\section{Renato Salinas}

Universidad de Santiago de Chile

Departamento de Ingenieria Mecánica

Avda. Bernardo O’Higgins 3363. Estación Central. Santiago - Chile

E-mail: renato.salinas@usach.cl

\section{Gastón Lefranc}

Pontificia Universidad Católica de Valparaíso

Escuela de Ingenieria Eléctrica

Avda. Brasil 2147. Valparaiso - Chile

E-mail: glefranc@ucv.cl

\begin{abstract}
This paper presents an Ontology Model of necessities and decisions for a cooperative community of heterogeneous robotic agents. Based on an ant community, it defines the characteristics of a collaborative and cooperative community of robots, using multi agent theory where each robot shares information with others robots in the community, to accomplish a common objective.

Keywords: Robotics, Intelligent Agents, Multi agents, Collaborative and Cooperative Robotics, Long-range-dependent, network layer, network traffic, selfsimilar process.
\end{abstract}

\section{Introduction}

Collaborative and Cooperative tasks are used in robotic agents, where the knowledge is shared; there exist communication to talk to the others robots where the area to the tasks is located and which decision that they have make, according to the necessities. These works have the hierarchy characteristics similar to that presented in nature, especially in the animal kingdom, where the most interesting are the behavior of bees, ants and termites, communicating where are the foods and the decisions that they have to take, according to the necessities. Based on this group behavior, these insects are intelligent agents designed by nature.

The agents can be simulated in a computer and put in group of robots that will be able to do tasks in coordinating way, where the decisions are taken with the group characteristics. The tasks in a community of collaborative and cooperative robots have increased in complex way, meaning the tasks cannot be done with only one robot, but needing a heterogeneous community of robots.

This heterogeneity of collective robots produces new challenges, adds a new difficulty to collective robotics, such as the aptitude to coordinate individuals with multiple qualities of an intelligent way; and to solve a specific goal working together and taking into account all the characteristics. To solve a certain task, each of them fulfills a specific function with which the 
rest must be able to coexist, the Satisfactory results by means of the union of their qualities, and work together [1].

There exist several methodologies for building multi agent systems. Few of them address the information domain of the system. It is as important as the representation of the system in the information domain is the various agents' information domain view. Heterogeneous systems can contain agents with differing data models, a case that can occur when reusing previously built agents or integrating legacy components into the system. Most existing methodologies lack specific guidance on the development of the information domain specification for a multi agent system and for the agents in the system. An appropriate methodology for developing ontology must be defined for designers to use for specifying domain representations in multi agent systems. The existing methodologies for designing domain ontologies are built to describe everything about a specific domain; however, this is not appropriate for multi agent systems because the system ontology should only specify the information required for proper system execution. The system ontology acts as a prerequisite for future reuse of the system, as the ontology specifies the view of the information domain used by the multi agent system. Any system that reuses the developed multi agent system must ensure that the previously developed system ontology does not conflict with the ontology being used in the new system [2]. Once the system ontology is constructed, a multi agent system design methodology should allow the analyst to specify objects from the data model as parameters in the conversations between the agents. To ensure the proper functionality of the multi agent system, the designer must be able to verify that the agents have the necessary information required for system execution. Since the information is represented in the classes of the data model, the design of the methodology must show the classes passed between agents $[3,4]$.

In this paper is presented an Ontology Model of necessities and decisions for a cooperative community of heterogeneous robotic agents based on an ant community. It defines the characteristics of collaborative and cooperative community of robots, using multi agent theory where each robot shares information with others robots in the community, to accomplish a common objective.

\section{Description of the problem}

In general, the complexity of the tasks added to the lack of constant structure in the environment, does not allow a homogeneous and structured community should be capable to fulfill the aims raised of an ideal way. Nevertheless, these limitations of capacities can be covered if different technologies are integrated; applying the heterogeneity in the architecture added to intelligent behaviors handled by means of Multi Agent Systems - MAS.

It is important to create MAS capable of controlling a heterogeneous community of robots in order to exhibit cooperation and collaboration among them, reaching the proposed aim. There are two concepts that have to be clarified, how the members of the community must be interrelated to the moment to make the work; and cooperation and collaboration.

Cooperation and collaboration is not the same thing. To collaborate is to contribute, is to give help (in knowledge or work) to do something, is to share the same proposition and the common goals. To cooperate is a collective work with a common goals, it means working together simultaneously, to have interactions of the collective work and interchange of ideas [5].

The cooperative and collaborative environments seek to transform heterogeneous groups into intelligent, flexible and autonomous communities. The community does not need having subordination; this means that the community has no teachers and apprentices nor masters and slaves; the agency is a mere way of communication towards the exterior, to send of results or requests of support $[6,7]$. 
In some communities, the robots communicate to a robot agency, to send reports outside of the community. In a heterogeneous community of robots, the communication between the robots must be in an egalitarian form, without intermediaries. Each of them has to have the capacity of direct connection with its partners, without establishing first the communication with the agency.

Briefly, it is important to have a MAS capable of provoking cooperation and collaboration, generating intelligence, flexibility and autonomy, without subordination, to arrive to results obtained from actions realized as consequence of consensus decisions $[1,8-10]$.

\section{Description of the organization of the community}

The community is formed by heterogeneous robots; each one is specializing in specific functions, which it helps in the achievement of the common goals.

Inside the community, every robot must report its characteristics to the rest of the community, in order to generate knowledge that it allows to determine which of its qualities are adapted to a specific works. Every robot has responsibilities, which will be resolved by consensus of the community, and it will have to realize its actions without being an obstacle to its companions, and giving any help that is necessary in unforeseen moments.

To realize the work, and unlike the existing robotic communities, a leader does not exist hence, the communication, transfer of information, and capture of decisions is of "all with all", where every contribution has the same value for the community.

If we base the study on a community of ants, these have behaviors that lead them to achieving its goals, though an ant alone is not capable of feeding and defending its anthill, millions of them can do it. In turn, a robot is not capable of realizing tasks that need major capacities that those that it possesses, but a group of them that brings together as a whole all the characteristics necessary, it can realize it.

Considering a group of agents, natural or artificial, which must come to an aim it can say that: (a) The ants (natural agents) possess intrinsic behaviors of communication, work and capture of decisions. (b) The robots (artificial agents) possess behavior learned or incorporated by means of programming which is based on predefined ontologies.

To manage to obtain a "natural behavior" in a robotic community modularization of every action realized by the natural agents in an artificial agent is based in the observation of the nature.

\section{Systems of Ontologies of Communication}

Every robot must know the directions of its community, or detect what signs are available, to be able to send the requests of connection and initiate the communicative act that will coordinate the execution of the tasks to realize. For this connection, three agents are needed: one agent capable of detecting signs, and to check the existing directions, one agent to request connection and other one to accept the request (Fig. 1).

On the other hand, whenever a new member joins the community, it has to report to its companions which are its characteristics and the functions for those that it was designed. For that purpose, it needs to have an agent that it should allow it to deliver its "curriculum" to the rest of the community, and in turn, it needs an agent capable of catching the information relating to each of its new collaborators. (Fig. 1).

During the accomplishment of the tasks, certain needs arise when in an individual is not capable of solving the task. In this case, it requests help to others. This implies that every 
individual has the aptitude to communicate its needs and in turn to process requests raised from others. A way of solving this problem is by means of agents in charge of realizing these tasks (Fig. 2).

Besides, it is necessary to have an agent capable of trying the need and to generate an action that could cover this need, based on the knowledge that it has, or to declare itself unable to realize something of usefulness. In brief, there needs an agent capable of making an individual decision.

\section{Ontology System of Making of Decisions}

In the execution of a cooperative and collaborative work, the communities of robotic agents face problems that need of rapid solution, even if its behavior is intrinsic in them and present certain characteristics of collective memory. They have to take decisions that in some cases involve to sacrifice some members of the colony. For it, when a need is communicated and it receives several individual answers to that aptitude to cover the need, the community must decide which of the offers is better, or how to coordinate them. For it, there can be applied different concepts based on the ontologies of decision in which the robotic MAS is sustained.

The last instance, before realizing the pertinent assignments to cover a need, is the taking of Decisions (D), where the conducts of the community meet reflected with major force, from the coordination up to the cooperation. Unlike the traditional focus in the collective robotics, in the community of robotic agents there appears a new concept, the consensus. Any decision taken must be realized by mutual agreement for the whole community that it is directly faced to a problem - Fig. 3 .

The Making of Decisions carries out three different forms, commonly used among human groups:

Decision for Similarity (DS): This one is taken when more than one individual presents the same solution, expressed of different way; the community may take both as different, and nevertheless it has to have the aptitude to detect the similarities among them and to obtain the unique solution. Yet, when there are significant differences between the offers realized, it must be feasible to unite the similarities among them and to optimize the differences to obtain the final solution that will be applied.

Decision for Quality (DC): This one turns out to be one of the most complexes since the robots must be capable of determining which of all the offers is the optimal, or the best solution. This requires that to community possesses another human characteristic, the

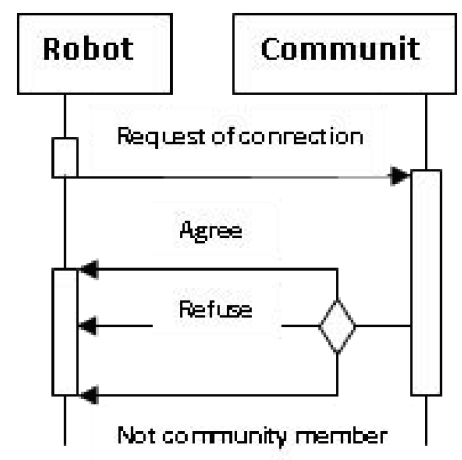

Figure 1: FIPA Protocol for community of Robotic Agents. 


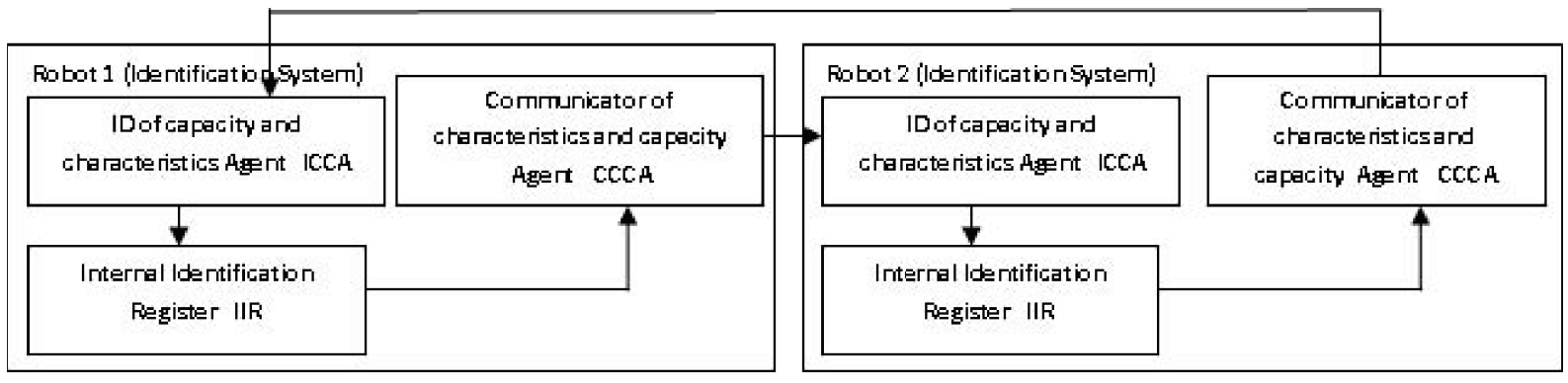

Figure 2: Architecture of knowledge behaviors for community of Robotic Agents.

intelligence, which brings the artificial intelligence, besides needing a major quantity of resources assigned to the Making decisions.

Decision for Majority (DM): This one refers to the choice of a solution from the generated offer more time, this solution goes of the hand in the majority of the times of the decision for similarity, since it turns out slightly probable that two or more agent components of robots with different characteristics and particular knowledge generate exactly equal solutions. The decision for majority implies reducing the number of offers by means of the assimilation, then there determining which is the accepted solution by means of the acceptance of the members' major quantity.

The behavior (similar to the human being) assigned to the community of robotic agents, goes directly related to the solution of problems. It is for it that the actions to take realize in a sequenced way being careful not to omit any of them in order not to present faults to the moment of it determines the suitable way of handling a certain situation arisen during the palliation of pertinent labors for the fulfillment of an aim.

On the other hand, the Satisfactories generally they turn out to be inactive individuals of the colony, already be that they are in the nest, or that have stopped its labors inside the community. These Agents Robots are capable of solving problems and of covering the needs of its companions as they were described in the previous point.

The general way of obtaining the Satisfactory determined by means of the process that culminates in the Making of Decisions, is by means of communicative acts which allow to deliver information to other members of the colony on what it is looked, in order that these could provide it. In a graphical form this sequence of actions is represented in Fig. 4.

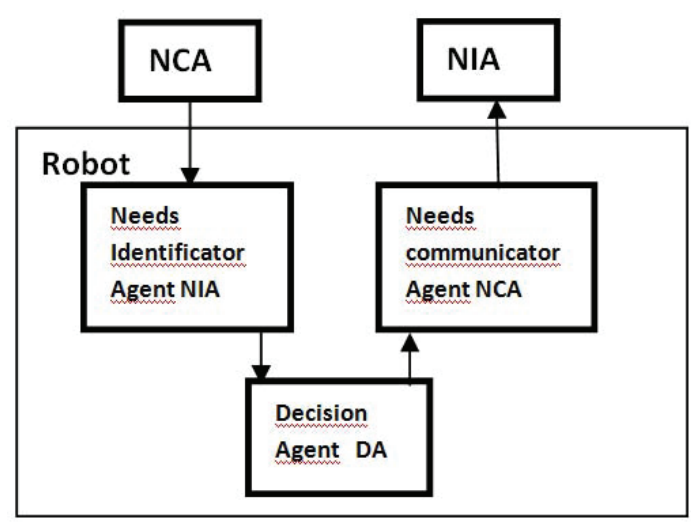

Figure 3: Architecture for making decisions in a community of Robotic Agents. 


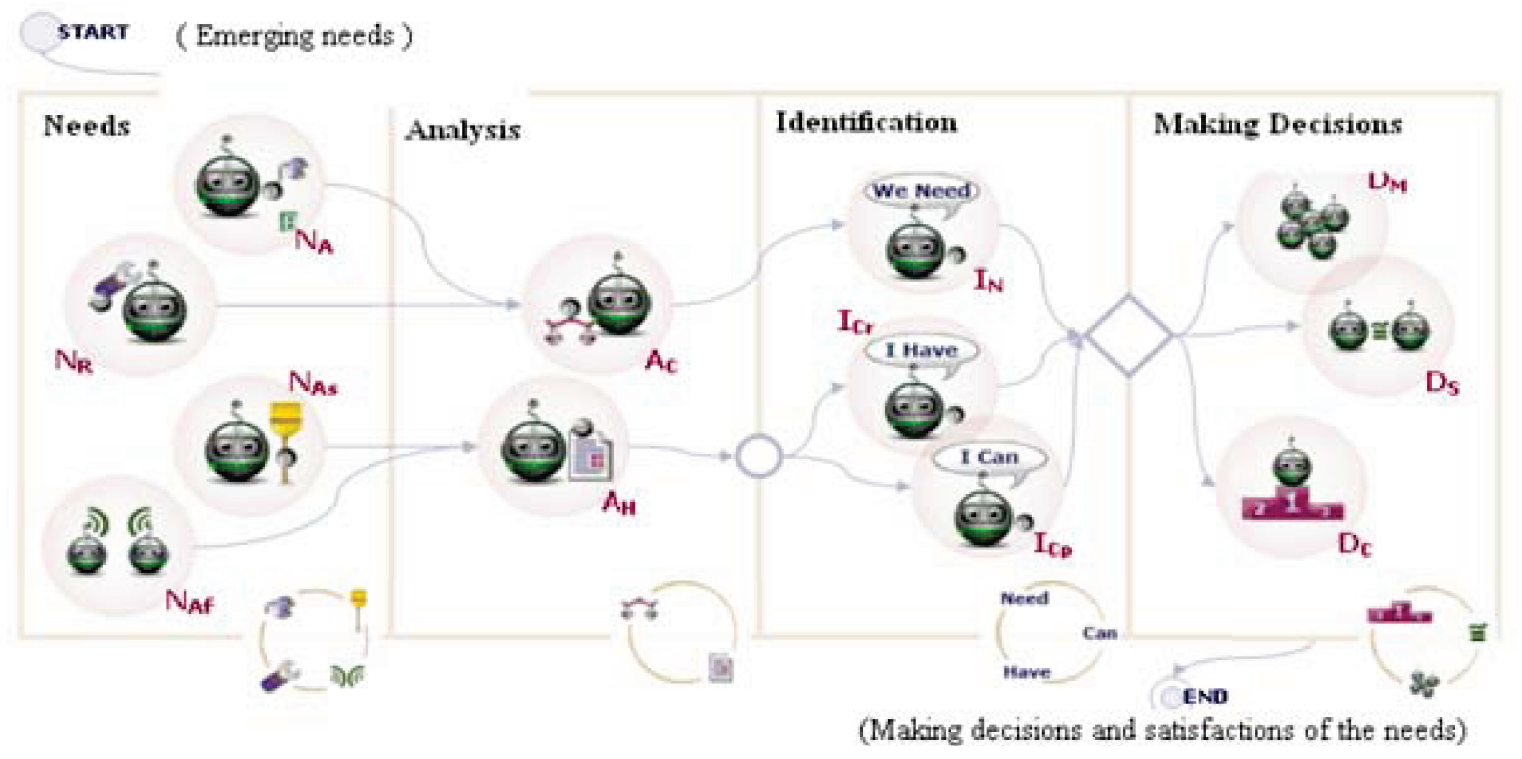

Figure 4: Sequence of actions for the search of a Satisfactory decision.

In a robotic community, every individual must have a small base of knowledge handled by an agent which will determine those actions can be used in the future and which not, beside to determine which are those situations that must be reported to the rest of the community to create a collective memory.

Likewise, the robots must possess an agent capable of Making a record of mistakes and correct them, registering also the above mentioned alteration. Also it has to have the aptitude to eliminate the knowledge that is unnecessary or is obsolete, to avoid information garbage inside the robot and its community.

\section{Ontologies for Needs}

These types of Ontologies define the particularities of every type of existing need. Nowadays, there are four basic needs, the nourishment, affiliation, assignment and repair. Each of them possesses certain points by means of which there can be associated an individual and to a labor, bequeathing this way to facilitating the take of decisions in the active community. Each of these needs possesses a particular class, these are:

Class Nourishment: This one describes the levels of discharge of energy that produce some problem in a robot, and defines the possible solution to the above mentioned mishap. The table 1 shows one of the subclasses that shape the class Nourishment.

Class Affiliation: This one describes the most particular need of all, the affiliation. This one takes place at the arrival of an individual to the active community and defines what must be fulfilled in order that this one is accepted by who will be its companions of Making place the affiliation of the new individual to the group. The table 2 shows one of the subclasses that shape the class Affiliation.

Class Assignment: This one describes the need of union between an individual and a labor. When it arises a certain task must be looked the one who realizes it, of compatibility exists with the Agents Robots inactive these they will be assigned, of not being like that a request 
will realize to the Agency Robots. They can be given in combination when more than one individual needs, and the total coverage of the Satisfactory does not exist in the active community. The table 3 shows one of the subclasses that shape the class Assignment.

Class Repair: This one describes possible damages somewhere or a piece of an individual, defining possibilities of repair, change or to send to workshop, depending on the severity of the fault. The table 4 shows one of the subclasses that shape the class Repair.

\begin{tabular}{ll}
\hline Subclass & Definition \\
\hline Level of Hunger & $\begin{array}{l}\text { Measure in per cent. It refers at the level of discharge that presents the } \\
\text { battery of nourishment of the robot. }\end{array}$ \\
Intermediate State & $\begin{array}{l}\text { It adduces to the state to which there will change the individual while } \\
\text { it is recharged (if it is left or it is still active or in wait) }\end{array}$ \\
Satisfactory & $\begin{array}{l}\text { It will determine depending on the unload if a loader or a derrick is } \\
\text { necessary. } \\
\text { Way of Connection }\end{array}$ \\
\hline
\end{tabular}

Table 1: Subclass of the class Nourishment

\begin{tabular}{|c|c|}
\hline Subclass & Definition \\
\hline Community Activates & $\begin{array}{l}\text { It determines the identificator of the active community to } \\
\text { which an individual is sent. }\end{array}$ \\
\hline Individual & It determines the identificator of the individual who is sent. \\
\hline Minimal percentage of acceptance & $\begin{array}{l}\text { It determines the minimal percentage of approval that must } \\
\text { exist in order that the individual be accepted as member of } \\
\text { the community. }\end{array}$ \\
\hline
\end{tabular}

Table 2: Subclasses of the class Affiliation.

\begin{tabular}{ll}
\hline Subclass & Definition \\
\hline Labor & Definition of the labor to realize. \\
Satisfactory & $\begin{array}{l}\text { Determination of the type of suitable individual. } \\
\text { Compatibility with } O_{I}\end{array}$ \\
$\begin{array}{l}\text { Existence of compatibility with the Agents Robots inactive inside } \\
\text { the active community. (Alphanumeric chain which first charac- } \\
\text { ter is the number of Agents compatible Robots, followed by its } \\
\text { identificator). }\end{array}$ \\
$\begin{array}{l}\text { Package of request of compatible individuals to send to the Agency } \\
\text { (chain of characters where the first character defines the quantity } \\
\text { followed by the description of the Satisfactory). }\end{array}$ \\
\hline
\end{tabular}

Table 3: Subclasses of the class Assignment

In the communities of robotic agents, it is necessary to define each and every of the ontologies that there are forming the base of knowledge of the robotic agents, which are fundamentals to define the task that the community is capable of realizing.

In this work, it presents a proposition of the ontologies of connection, of decision and of needs, for a community of robotic agents in particular, which joined the development of intelligent agents, manages to form a type of social behavior very similar to the behaviors in the conducts presented by social groups such as the ants, which possess a highly developed instinct of collaboration and cooperation. 


\begin{tabular}{ll}
\hline Subclass & Definition \\
\hline Damaged Piece & It determines which is the piece that presents damage. \\
$\begin{array}{ll}\text { Level of damage } \\
\text { Capacity of change }\end{array}$ & It determines of percentage form the severity of the fault. \\
$\begin{array}{ll}\text { Intermediate State } & \text { It adduces to the state to which there will change the individual while } \\
\text { it is repaired (if it is left or it is still active or in wait) }\end{array}$ \\
$\begin{array}{l}\text { It determines that repairer is the most suitable, or if it turns out to be } \\
\text { more suitable if a derrick is requested. }\end{array}$ \\
\hline
\end{tabular}

Table 4: Subclasses of the class Repair

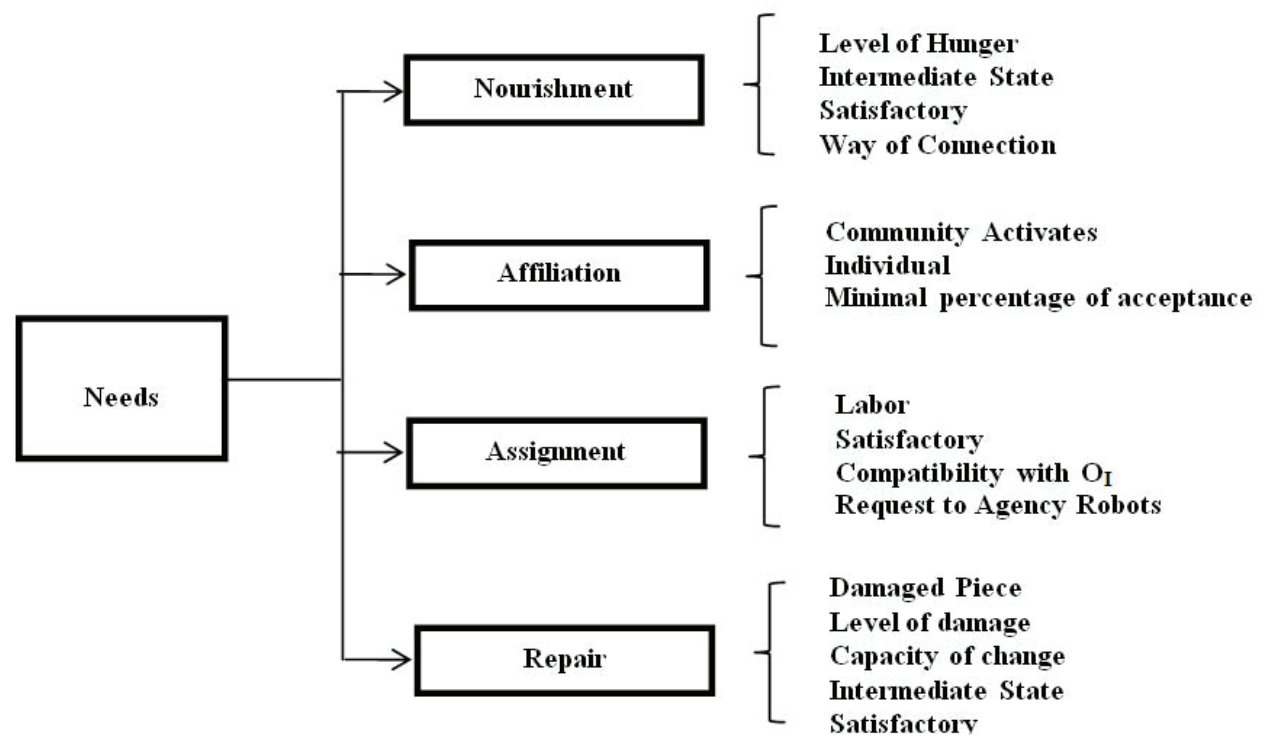

Figure 5: Ontology of Needs

The following image (Fig 5) presents a graph of the components of the classes of the Ontology of Needs.

\section{Conclusions}

In the communities of robotic agents, it is necessary to define each and every one of the ontologies that there are forming the base of knowledge of the robotic agents, which are fundamental to define the task that the community is capable of realizing.

In this work, it presents a proposition of an Ontology Model for a cooperative community of heterogeneous robotics agents. It defines the characteristics of collaborative and cooperative community of robots, using multi agent theory where each robot shares information with others robots in the community, to accomplish a common objective. The ontologies are for connection, for decisions and for needs, for a community of robotic agents in particular, which joined the development of intelligent agents, manages to form a type of social behavior very similar to the behavior by social groups such as the ants.

\section{Bibliography}

[1] Lefranc, G. "Colony of robots: New Challenge", Int. J. of Computers, Communications \& Control, ISSN 1841-9836, E-ISSN 1841-9844, Vol. III (2008), Suppl. issue: IJCCC 2008, pp. 
92-107.

[2] Ellips Masehian, and Davoud Sedighizade, "Classic and Heuristic Approaches in Robot Motion Planning - A Chronological Review". Proceedings of World Academy of Science, Engineering and Technology Volume 23, August 2007.

[3] McGuinness, D.L., Fikes, R., Rice, J. and Wilder, S. An Environment for Merging and Testing Large Ontologies. Principles of Knowledge Representation and Reasoning: proceedings of the Seventh International Conference. A. G. Cohn, F. Giunchiglia and B. Selman, editors. San Francisco, CA, Morgan Kaufmann Publishers. 2000.

[4] Supnithi T., Inaba A., Ikeda M., Toyoda J., Mizoguchi R., 1999. "Learning goal ontology supported by learning theories for Opportunistic Group Formation". Proc. of AIED99, pp. $67-74$.

[5] Brophy S., Biswas G., Katzlberger T., Bransford J. and Schwartz D., 1999. "Teachable agents: Combining Insights from Learning Theory and Computer Science". In S. P. Lajoie and M. Vivet (Eds.), Artificial Intelligence in Education, pp. 21-28.

[6] Sloczinski, H. Lucila Maria Costi Santarosa, "Aprendizagem Coletiva em Curso Mediado Pela Web", VII Congresso Iberoamericano de Informática Educativa, 2003.

[7] Nwana H., 1996. "Software Agents: An Overview". Vol. 11, No 3, pp. 205-244. Cambridge University Press.

[8] Paquette G., 1999. "Meta-Knowledge representation for learning scenarios engineering". Proceedings of AI-Ed, 1999.

[9] Posadas J., 2003. "Arquitectura para el control de robots móviles mediante delegación de códigos y agentes". Tesis Doctoral. Universidad Politécnica de Valencia.

[10] Soller, A. Linton, F., Goodman, B., and Lesgold, A., 1999. "Toward Intelligent analysis and support of Collaborative learning interaction". Proceedings of the Ninth International Conference on Artificial Intelligence in Education, Le Mans, France, 75-82.

[11] Russell, S., Norvig, P., 1995. "Artificial Intelligence: A Modern Approach". Ed. Prentice Hall.

[12] Wooldridge M. and Jennings R., 1995. "Intelligent agents: Theory and practice". The Knowledge Engineering Review, 10(2): pp. 115-152. 